\title{
Alterations in Corticotropin-Releasing Factor-like Immunoreactivity in Discrete Rat Brain Regions After Acute and Chronic Stress
}

\author{
Phillip B. Chappell, ${ }^{\star}$ Mark A. Smith, ${ }^{*}$ Clinton D. Kilts, ${ }^{\star}+$ Garth Bissette, ${ }^{*}$ James Ritchie, ${ }^{*}$ Carl \\ Anderson, ${ }^{*}$ and Charles B. Nemeroff ${ }^{*} \dagger+$ \\ Departments of *Psychiatry, †Pharmacology, and the $\neq$ Center for Aging and Human Development, Duke \\ University Medical Center, Durham, North Carolina 27710
}

Corticotropin releasing factor (CRF) may regulate endocrine, autonomic, and behavioral responses to stress. Evidence indicates that CRF-like immunoreactivity (CRF-LI) is widely distributed throughout the CNS. In this study, the distribution of CRF-LI was determined in 36 rat brain regions by combined radioimmunoassay-micropunch dissection techniques and the effect of stress on CRF-LI was investigated, using a chronic stress model that induces endocrine changes in rats similar to those seen in depressed humans.

A control group of rats was handled daily. An acute stress group was subjected to $3 \mathrm{hr}$ of immobilization at $4^{\circ} \mathrm{C}$, while a chronic stress group was exposed to unpredictable stressors. Thirty-six brain regions were microdissected by the technique of Palkovits and assayed for CRF-LI, using a specific antiserum to ovine CRF.

CRF-LI was detected in most regions. In controls, the highest concentrations were found in the arcuate nucleus/median eminence, the hypothalamic paraventricular (PVN) nucleus, and the periventricular nucleus. The next highest levels were found in the raphe nuclei and dorsal vagal complex. CRF-LI was well represented in the locus coeruleus (LC); in the central, cortical, and medial amygdaloid nuclei; and in the bed nucleus of the stria terminalis. Low concentrations occurred in the hippocampus and cerebrocortical regions. Appreciable concentrations were detected in midbrain and brain stem regions.

Acute stress reduced CRF-LI in the arcuate nucleus/median eminence (ME) (by 52\%) and in the median preoptic (MPO) nucleus (by 32\%) and doubled its concentration in the locus coeruleus. Chronic stress produced changes similar to those of acute stress in the arcuate nucleus/median eminence (ME) and locus coeruleus, while significantly increasing CRF-LI in the anterior hypothalamic and periventricular nuclei and significantly decreasing CRF-LI in the dorsal vagal complex (DVC). These results suggest that stress alters CRF-I $I$ in brain regions that have been implicated in the CNS response to stress.

Harris (1948) postulated that activation of the pituitary-adrenal axis during stress was mediated by a hypothalamic substance released into the hypothalamo-hypophysial portal system. This substance, corticotropin-releasing factor (CRF), was finally identified by Vale and his colleagues (1981) as a 41-amino acid

\footnotetext{
Received Dec. 28, 1985; revised Apr. 21, 1986; accepted Apr. 24, 1986.
}

This work was supported by Grants NIMH MH-39415 and MH-39967. C.B.N. is supported by a Nanaline H. Duke fellowship from Duke University Medical Center. The technical assistance of Laurcl O'Connor, the statistical assistance of Gordon Daughtry, and the assistance of Molly McMullen in preparation of this manuscript are gratefully acknowledged.

Correspondence should be addressed to Dr. Charles B. Nemeroff, Department of Psychiatry, Box 3859, Duke University Medical Center, Durham, NC 27710. Copyright (c) 1986 Society for Neuroscience $0270-6474 / 86 / 102908-07 \$ 02.00 / 0$ peptide, and shown to stimulate ACTH and $\beta$-endorphin secretion from the anterior pituitary (Rivier et al., 1982a).

The importance of CRF in the response to stress is supported by the obscrvation that systemic administration of a CRF antiserum significantly reduced plasma ACTH levels in ether-stressed rats (Rivier et al., 1982b). Thus, as predicted, CRF appears to play an essential role in the pituitary-adrenal stress response. However, recent evidence suggests that CRF may also have extra-hypophysiotropic functions. Intracerebroventricular injection of CRF elicits behavioral activation of rats (Britton et al., 1982; Sutton et al., 1982), regulates activity of the sympathoadrenomedullary system (Brown et al., 1982; Fisher et al., 1982), inhibits food consumption (Levine et al., 1983) and sexual behavior (Sirinathsinghji et al., 1983), and excites neurons in specific CNS loci, including the locus coeruleus (Ehlers et al., 1983; Valentino et al., 1983). Many of these effects of centrally administered exogenous CRF are reminiscent of the signs and symptoms of depression in humans (Baldessarini, 1983). Furthermore, radioimmunoassay (Fischman and Moldow, 1982; Moldow and Fischman, 1982; Palkovits et al., 1985) and immunohistochemical (Cummings et al., 1983; Sawchenko and Swanson, 1985; Swanson et al., 1983) studies have demonstrated that CRF-like immunoreactivity exhibits a widespread and uneven distribution throughout the mammalian brain. These findings, taken together, raise the possibility that CRF might regulate the stress response within the CNS as well as through peripheral mechanisms.

Central effects of CRF are also of interest because of the increased activity of the hypothalamic-pituitary-adrenal (HPA) axis in many patients with depression, as evidenced by nonsuppression of plasma cortisol after administration of the synthetic glucocorticoid dexamethasone (Carroll et al., 1976). Recently we have demonstrated that many depressed patients do, in fact, have elevated CSF concentrations of CRF-like immunoreactivity (CRF-LI) (Nemeroff et al., 1984), suggesting that hyperactivity of CRF-containing neurons may be associated with, or even contribute to, the pathophysiology of depression. Furthermore, neurotransmitters such as norepinephrine, acetylcholine, and serotonin seem to be involved not only in depression (Weiss et al., 1981), but also in the regulation of CRF release from the hypothalamus during stress.

The purpose of this study was to characterize the distribution of CRF in the CNS of the rat and to determine whether acute or chronic stress alters the concentration of CRF in discrete brain nuclei. The development of a specific radioimmunoassay for CRF (Vale et al., 1983b) enabled us to determine the concentration of this peptide in various brain nuclei microdissected by the punch technique of Palkovits (1973). We mapped changes in the concentration of CRF in 36 different rat brain regions following acute stress or a chronic stress protocol designed to maximize the unpredictable nature of the stressors (Katz et al., 


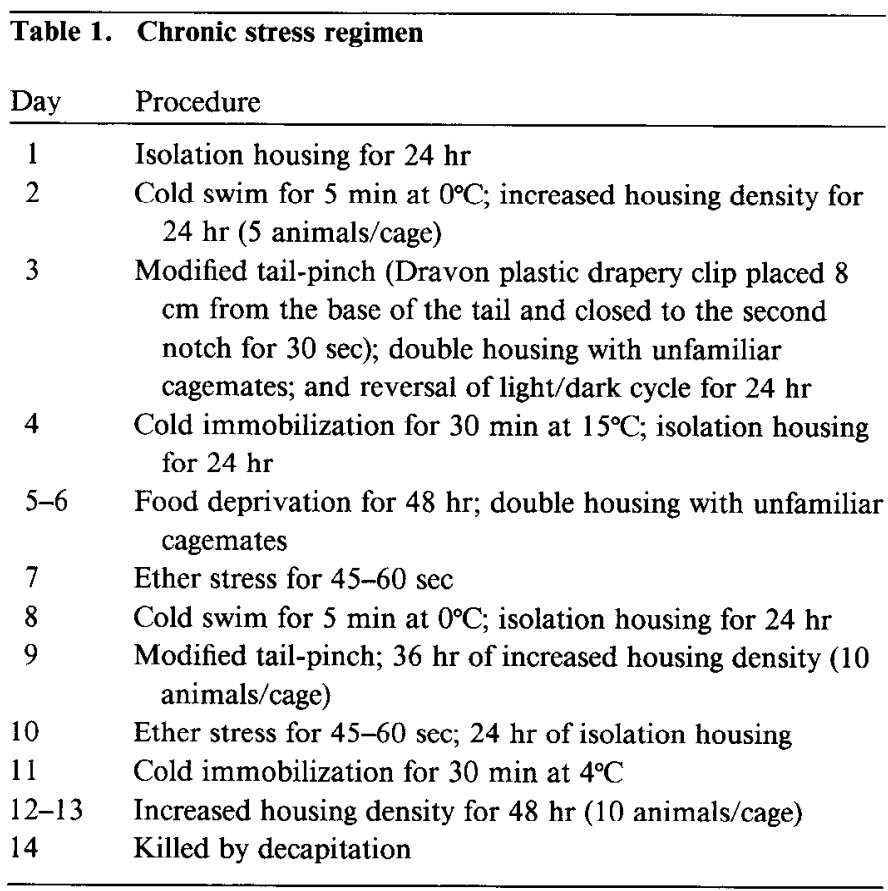

1981). We chose this later protocol in order to prevent the animals from developing tolerance to the stress, as they might have if the same stressor were repeated at regular intervals. In addition, this chronic stress model has been shown to induce endocrine changes in rats similar to those seen in humans with depression (Katz, 1982; Katz et al., 1981).

\section{Materials and Methods}

\section{Animals}

Thirty adult male Sprague-Dawley rats (Charles River Laboratories), weighing 150-250 gm at the start of the experiment, were housed 2 per cage, with food and water available ad libitum in an environmentally controlled animal facility $(12 \mathrm{hr} / 12 \mathrm{hr}$ light/dark cycles with lights on at 0700 ).

\section{Stress procedures}

Ten control rats and 10 rats assigned to the acute stress group were handled daily for 13 consecutive days in order to accustom them to the presence of humans and to minimize the effects of nonspecific stress. The acute stress group was subjected to acute immobilization stress, being restrained and placed supine in a $4^{\circ} \mathrm{C}$ cold room for $3 \mathrm{hr}$ (from 1000 to 1300), as previously described (Nemeroff et al., 1982). Rats in the control and acute stress groups were killed by decapitation, care being taken to first transport them in a nonstressful manner, as previously described (Uphouse et al., 1982). At death, trunk blood was collected, centrifuged at $1500 \mathrm{rpm}$ at $4^{\circ} \mathrm{C}$ for $15 \mathrm{~min}$, and plasma was separated and frozen at $-70^{\circ} \mathrm{C}$ for subsequent assay of corticosterone and ACTH. After decapitation, the brains and pituitaries were rapidly removed, frozen on dry ice, and stored at $-70^{\circ} \mathrm{C}$. Adrenal glands were also removed and their wet weights recorded.

In a modification of a previously described chronic stress regimen (Katz et al., 1981), a third group of 10 rats was subjected to a $13 \mathrm{~d}$ course of unpredictable stressors. Various stressors were administered in order to maximize the unpredictability of both the type of stress and its timing. The details of the chronic stress paradigm are presented in Table 1 . On day 14 these rats were also killed; their brains, pituitaries, trunk blood, and adrenals were obtained as previously described.

\section{Microdissection and sample preparation of brain regions}

The microdissection of brain slices has been described in detail elsewhere (Palkovits and Brownstein, 1983). In brief, brains were frozen ventral side up on dry ice and sliced into $300-\mu \mathrm{m}$-thick coronal sections in a cryostat at $-10^{\circ} \mathrm{C}$. With the exception of raphe nuclei, nuclei were
Table 2. Effect of acute and chronic stress on adrenal weight, plasma ACTH and corticosterone concentration, and pituitary ACTH content

\begin{tabular}{cccc} 
& Controls & $\begin{array}{l}\text { Acute } \\
\text { stress }\end{array}$ & $\begin{array}{l}\text { Chronic } \\
\text { stress }\end{array}$ \\
\hline $\begin{array}{c}\text { Adrenal weight } \\
(\mathrm{mg} \pm \mathrm{SEM})\end{array}$ & $42 \pm 2$ & $43 \pm 2$ & $51 \pm 2^{*}$ \\
$\begin{array}{c}\text { Plasma ACIH } \\
(\mathrm{pg} / \mathrm{ml} \pm \mathrm{SEM})\end{array}$ & $123 \pm 9$ & $186 \pm 21^{* *}$ & $122 \pm 6$ \\
$\begin{array}{c}\text { Plasma corticosterone } \\
(\mu \mathrm{g} / \mathrm{dl} \pm \mathrm{SEM})\end{array}$ & $16 \pm 3$ & $51 \pm 5^{* * *}$ & $29 \pm 5^{*}$ \\
$\begin{array}{c}\text { Pituitary ACTH content } \\
(\mathrm{ng} / \text { pituitary } \pm \text { SEM) }\end{array}$ & $4.03 \pm 0.41$ & $3.28 \pm 0.30$ & $3.40 \pm 0.34$
\end{tabular}

Data were analyzed by 1-way ANOVA followed by Scheffe's test for intergroup differences. Each group consisted of 10 subjects.

* Significantly different from controls and acute stress group, $p<0.05$.

** Significantly diffcrent from controls and chronic stress group, $p<0.05$.

*** Significantly different from controls and chronic stress group, $p<0.01$.

removed bilaterally, using thin-walled stainless steel tubing (internal diameters: $0.57,0.75,0.91$, and $1.15 \mathrm{~mm}$ ). Samples were blown into polypropylene microcentrifuge tubes, placed on dry ice, and stored at $-80^{\circ} \mathrm{C}$ until assayed.

Micropunched samples were homogenized by ultrasonic disruption in $500 \mu 11 \mathrm{~N} \mathrm{HCl}$. Following centrifugation at $10,000 \mathrm{rpm}$ at $4^{\circ} \mathrm{C}$ for $15 \mathrm{~min}$ in a microcentrifuge, duplicate $200 \mu \mathrm{l}$ aliquots were removed, lyophilized in $10 \times 75 \mathrm{~mm}$ borosilicatc glass tubes, and stored at $80^{\circ} \mathrm{C}$ until assayed. Pellets were lyophilized, stabilized in $300 \mu 11 \mathrm{~N} \mathrm{NaOH}$, and assayed for protein content by the method of Lowry et al. (1951).

\section{$C R F$ radioimmunoassay}

The concentration of CRF-LI in the individual brain nuclei was measured in duplicate by modification of a previously described specific radioimmunoassay (RIA) for CRF (Vale et al., 1983b), using an antiserum (oC30) raised in rabbits against ovine CRF. In brief, the lyophilized samples were reconstituted in $200 \mu \mathrm{l}$ RIA buffer (SPEAB buffer: $100 \mathrm{~mm} \mathrm{NaCl}, 50 \mathrm{~mm} \mathrm{Na}_{2} \mathrm{HPO}_{4}, 25 \mathrm{~mm}$ EDTA, $0.1 \%$ sodium azide, $0.1 \% \mathrm{BSA} / 0.1 \%$ Triton $\mathrm{X}-100, \mathrm{pH} 7.3$ ) and incubated at $4^{\circ} \mathrm{C}$ for $18 \mathrm{hr}$ with $100 \mu 1$ oC30 antibody at a dilution of $1: 35,000$. Then $50 \mu \mathrm{l}$ of the radiolabeled CRF trace, ${ }^{125}{ }^{2}-$ Tyr $^{0}$-rat/human CRF $(20,000 \mathrm{cpm})$, prepared with chloramine-T and purified by HPLC, exactly as described by Vale et al. (1983), was added. After an additional $6 \mathrm{hr}$ at $4^{\circ} \mathrm{C}$, goat anti-rabbit serum (second antibody; Arnel Products, NY) was added to precipitate the bound CRF (Nemeroff et al., 1984).

CRF concentrations of all the brain regions were assayed in a single RIA. The sensitivity of the assay was $2.5 \mathrm{pg} /$ tube and the intra-assay coefficient of variation was $9 \%$. The CRF antibody does not detect any other known peptides, including sauvagine and urotensin I, and does not cross-react with vasopressin, ACTH, or angiotensin II (Gibbs and Vale, 1982). CRF immunoreactivity in brain extracts subjected to HPLC has been shown to cochromatograph with synthetic $\mathrm{CRF}_{1-41}$ (M. A. Smith et al., unpublished observations).

\section{ACTH radioimmunoassay}

Plasma ACTH concentrations were determined by a sensitive and specific RIA (Gutkowska et al., 1982; Orth, 1978), using an antiserum raised in rabbits against thyroglobin-conjugated $\mathrm{ACTH}_{11-24}$ that gives optimal binding at a final dilution of 1:600,000. The assay typically has a sensitivity of $1 \mathrm{pg} / \mathrm{ml}$ in plasma, and of the material bound by this antiserum in plasma, $95 \%$ is authentic ACTII (K. R. Krishnan and J. M. Ritchie, unpublished observations). All plasma samples were extracted prior to assay, using C-18 Sep-pak cartridges (Waters Associates, Milford, MA), to minimize nonspecific binding effects from undiluted plasma. The frozen pituitaries were prepared by sonic disruption in 500 $\mu 11 \mathrm{~N} \mathrm{HCl}$, followed by centrifugation $\left(5000 \mathrm{rpm} \times 15 \mathrm{~min}\right.$ at $\left.0^{\circ} \mathrm{C}\right)$. The supernatant was then extracted using C-18 Sep-pak cartridges, lyophilized, and reconstituted in ACTH RIA buffer $\left(0.055 \mathrm{M} \mathrm{Na}_{2} \mathrm{PO}_{4}\right.$, $0.02 \%$ sodium azide, $1.25 \%$ normal rabbit serum, $0.02 \%$ poly-L-lysine, $0.05 \%$ Triton $\mathrm{X}-100, \mathrm{pH} 7.4$ ) for assay at an antibody dilution of 1 : 4000 . 


\begin{tabular}{|c|c|c|c|}
\hline Brain area & Controls & Acute stress & Chronic stress \\
\hline Median eminence/arcuate nucleus & $5054 \pm 674$ & $2425 \pm 528^{*}$ & $2783 \pm 572^{*}$ \\
\hline Paraventricular nucleus & $498 \pm 44$ & $478 \pm 81$ & $361 \pm 45$ \\
\hline Periventricular nucleus & $316 \pm 15$ & $326 \pm 16$ & $440 \pm 41^{* *}$ \\
\hline Medial preoptic nucleus & $142 \pm 11$ & $97 \pm 5^{* * *}$ & $119 \pm 10$ \\
\hline Lateral preoptic nucleus & $86 \pm 6$ & $86 \pm 7$ & $98 \pm 8$ \\
\hline Anterior hypothalamic nucleus & $93 \pm 7$ & $132 \pm 20$ & $166 \pm 11^{* * * *}$ \\
\hline Ventromedial nucleus & $97 \pm 15$ & $145 \pm 30$ & $121 \pm 19$ \\
\hline Dorsomedial nucleus & $114 \pm 7$ & $111 \pm 5$ & $117 \pm 10$ \\
\hline
\end{tabular}

\section{Corticosterone assay}

Plasma corticosterone concentrations were determined using a modification of Murphy's competitive protein-binding radioassay, with a sensitivity of $0.3 \mu \mathrm{g} / \mathrm{dl}$, as previously described (Murphy, 1967; Ritchie et al., 1985). Sample radioactivity was measured using a Packard 460 liquid scintillation counter.

\section{Statistical analysis}

All data are presented as means \pm SEM. Results for adrenal weight, plasma ACTH, and corticosterone concentrations, as well as for pituitary ACTH content, werc analyzcd by a 1-way analysis of variance (ANOVA) followed by Scheffe's test for multiple group comparisons. The effects of stress on CRF-LI concentrations in microdissected rat brain regions were analyzed by the Student-Newman-Keuls multiplerange test, following a one-way ANOVA and Cochran's $C$ test. The Bartlett Box $F$ test for analysis of homogeneity of variance was also employed. Where necessary, data were subjected to logarithmic transformation to correct for heterogeneity of variance (Remington and Schork, 1970).

\section{Results}

\section{ACTH and corticosterone}

As is shown in Table 2, acute stress produced a significant rise in plasma ACTH and corticosterone concentrations. Adrenal weight was unaffected by exposure to acute stress.

Following chronic stress, plasma corticosterone, but not ACTH, concentrations were increased. The rats exposed to chronic stress also exhibited a significant increase in adrenal weight.

Pituitary ACTH content was not affected either by acute or chronic stress.

Table 4. CRF concentration in cerebrocortical regions (pg/mg protein; mean \pm SEM)

\begin{tabular}{llll} 
Brain area & Controls & $\begin{array}{l}\text { Acute } \\
\text { stress }\end{array}$ & $\begin{array}{l}\text { Chronic } \\
\text { stress }\end{array}$ \\
\hline Medial prefrontal cortex & $22 \pm 1$ & $24 \pm 1^{*}$ & $20 \pm 1^{*}$ \\
Pyriform cortex & $28 \pm 2$ & $24 \pm 3$ & $24 \pm 2$ \\
Cingulate cortex & N.D. ${ }^{a}$ & N.D. & N.D. \\
Entorhinal cortex & $27 \pm 3$ & $24 \pm 3$ & $18 \pm 1$ \\
\hline
\end{tabular}

Data were analyzed by the Student-Newman-Keuls multiple range test following 1-way ANOVA, Cochran's $C$ test, and the Bartlett Box $F$ test for homogeneity of variance. Ten determinations were obtained for all brain regions.

${ }^{a}$ Not detectable.

* Significantly different from each other but not from controls, $p<0.05$.

\section{CRF distribution}

In the control (nonstressed) rats, CRF-LI was detected in 35 of 36 brain regions, the highest concentrations being in the hypothalamus (Table 3 ). Within this diencephalic brain region, the arcuate nucleus/median eminence (ME) contained the highest concentration, followed by the paraventricular (PVN) and periventricular nuclei. The medial preoptic (MPO), dorsomedial, lateral preoptic, anterior hypothalamic, and ventromedial nuclei contained similarly lower amounts.

Relatively low CRF-LI concentrations were found in the following neocortical regions: median prefrontal, pyriform, and entorhinal. In the cingulate cortex, CRF-LI was not reliably detected (Table 4).

In the limbic system (Table 5), the highest concentrations of CRF-LI were detected in the central and cortical nuclei of the amygdala and in the interstitial (bed) nucleus of the stria terminalis. The remaining amygdaloid nuclei (medial, basal, and lateral) also contained appreciable quantities of CRF-LI. The nucleus accumbens, medial and lateral septal nuclei, and the nucleus of the diagonal band, as well as the olfactory tubercles, substantia innominata, and the lateral habenula, contained moderate concentrations of CRF-LI. Relatively low concentrations of the peptide were detceted in the dorsal and ventral hippocampus.

All midbrain regions contained substantial concentrations of CRF-LI (Table 6). The zona compacta of the substantia nigra contained the highest CRF-LI concentration of any of the midbrain regions studied, while somewhat lower concentrations werc measured in the pars lateralis and zona reticularis of the substantia nigra. The periaqueductal gray and ventral tegmental area exhibited relatively high CRF-LI levels.

After the hypothalamus, the next highest CRF-LI concentrations were observed in the medial and dorsal raphe nuclei, regions known to be rich in serotonergic perikarya. The locus coeruleus (LC), comprised largely of adrenergic cell bodies, also contained a relatively high concentration of CRF-LI.

In the medulla, a substantial level of CRF-LI was detected in the dorsal vagal complex (DVC).

\section{Effects of acute and chronic stress}

In most of the brain regions studied, CRF-LI concentrations were unchanged by acute or chronic stress. However, as is shown in Table 3, acute stress markedly reduced CRF-LI in the arcuate nucleus/median eminence (down 52\%) and the MPO nucleus (down 32\%). In contrast to these results in the diencephalon, in the LC the concentration of CRF-LI was markedly increased (up 107\%) by acute stress. 
Table 5. CRF concentration in the limbic system (pg/mg protein; mean \pm SEM)

\begin{tabular}{|c|c|c|c|}
\hline Brain area & Controls & $\begin{array}{l}\text { Acute } \\
\text { stress }\end{array}$ & $\begin{array}{l}\text { Chronic } \\
\text { stress }\end{array}$ \\
\hline Olfactory tubercles & $94 \pm 7$ & $84 \pm 6$ & $78 \pm 5$ \\
\hline Nucleus tractus diagonalis & $64 \pm 4$ & $63 \pm 5$ & $58 \pm 7$ \\
\hline \multicolumn{4}{|l|}{ Septum } \\
\hline Lateral nucleus & $68 \pm 7$ & $52 \pm 5$ & $53 \pm 3$ \\
\hline Medial nucleus & $86 \pm 9$ & $118 \pm 10$ & $112 \pm 17$ \\
\hline Nucleus accumbens & $94 \pm 12$ & $91 \pm 6$ & $97 \pm 5$ \\
\hline \multicolumn{4}{|l|}{ Bed nucleus of the stria } \\
\hline terminalis & $136 \pm 14$ & $244 \pm 52$ & $253 \pm 45$ \\
\hline \multicolumn{4}{|l|}{ Amygdala } \\
\hline Cortical nucleus & $148 \pm 21$ & $118 \pm 10$ & $128 \pm 7$ \\
\hline Basal nucleus & $85 \pm 3$ & $100 \pm 6$ & $103 \pm 10$ \\
\hline Central nucleus & $192 \pm 17$ & $166 \pm 17$ & $166 \pm 19$ \\
\hline Medial nucleus & $110 \pm 10$ & $125 \pm 11$ & $120 \pm 8$ \\
\hline Lateral nucleus & $77 \pm 5$ & - & $80 \pm 4$ \\
\hline Dorsal hippocampus & $31 \pm 2$ & $32 \pm 2$ & $36 \pm 4$ \\
\hline Ventral hippocampus & $34 \pm 2$ & $35 \pm 3^{*}$ & $28 \pm 1^{*}$ \\
\hline Lateral habenula & $72 \pm 8$ & $57 \pm 4^{* *}$ & $87 \pm 8^{* *}$ \\
\hline Substantia innominata & $98 \pm 5$ & $108 \pm 7$ & $101 \pm 6$ \\
\hline
\end{tabular}

Data were analyzed by the Student-Newman-Keuls multiple range test following 1-way ANOVA, Cochran's $C$ test, and the Bartlett Box $F$ test for homogeneity of variance, except for the data on the lateral nucleus, which were analyzed by 1 -way ANOVA and Student's $t$ test (2-tailed). Ten determinations were obtained for all brain regions.

* Significantly different from each other but not from controls, $p<0.05$.

** Significantly different from each other but not from controls, $p<0.025$.

Following chronic stress, no effect on the concentration of CRF-LI in the MPO area was noted, though increases in the periventricular nucleus, anterior hypothalamic nucleus, and LC were seen. Chronic stress also produced a reduction in CRF-LI in the DVC, while acute stress had no cffect in this region (Fig. 1).

It is of particular interest that neither acute nor chronic stress produced significant changes in the CRF-LI content of the PVN hypothalamic nucleus, an important site of CRF biosynthesis. In addition, an important limbic structure, the bed nucleus of the stria terminalis, exhibited an approximate $80 \%$ rise in CRFLI concentration after acute and chronic stress, though this failed to achieve statistical significance, owing to higher than usual variance in both stress groups.

\section{Discussion}

The results of the present study with regard to the distribution of CRF-LI in nonstressed rats are similar but not identical to previous RIA studies. Fischman and Moldow (1982) measured CRF-LI conccntrations in relatively large hypothalamic and extrahypothalamic rat brain regions obtained by the dissection method of Glowinski and Iversen (1966), using an antibody raised in rabbits against synthetic ovine CRF and a tracer of ${ }^{125} \mathrm{I}-N$-Tyr ${ }^{0}$-ovine CRF. In a preliminary study, we also measured CRF-LI in rat brain regions disscetcd by a modification of the method of Glowinski and Iversen (1966), and obtained similar results in the hypothalamus, amygdala, frontal cortex, and midbrain (M. A. Smith, unpublished observations). However, in 3 other brain regions (thalamus, hippocampus, and striatum), our results revealed substantially lower CRF-LI concentrations than those of Fischman and Moldow (1982).

Palkovits et al. (1985) quantitated CRF-LI (determined as ng $\mathrm{CRF}-\mathrm{LI} / \mathrm{mg}$ protein) in 70 microdissected rat brain nuclei using an antibody against synthetic rat CRF. The lowest detectable
Table 6. CRF concentration in the midbrain and lower brain stem (pg/mg protein; mean \pm SEM)

\begin{tabular}{lcll} 
Brain area & Controls & $\begin{array}{l}\text { Acute } \\
\text { stress }\end{array}$ & $\begin{array}{l}\text { Chronic } \\
\text { stress }\end{array}$ \\
\hline $\begin{array}{l}\text { Midbrain } \\
\text { Ventral tegmental area }\end{array}$ & $134 \pm 11$ & $146 \pm 5$ & - \\
$\quad \begin{array}{l}\text { Subtantia nigra } \\
\quad \text { Zona reticularis }\end{array}$ & $94 \pm 7$ & $80 \pm 4$ & $83 \pm 10$ \\
$\quad \begin{array}{l}\text { Zona compacta } \\
\text { Pars lateralis }\end{array}$ & $190 \pm 13$ & $185 \pm 17$ & $159 \pm 11$ \\
$\quad \begin{array}{l}\text { Periaqueductal gray } \\
\text { Pons }\end{array}$ & $144 \pm 18$ & $132 \pm 27$ & $108 \pm 18$ \\
$\quad \begin{array}{l}\text { Medial raphe nucleus } \\
\text { Dorsal raphe nucleus }\end{array}$ & $241 \pm 18$ & $215 \pm 8$ & $229 \pm 13$ \\
$\quad$ Locus coeruleus & $148 \pm 9$ & $306 \pm 50^{*}$ & $321 \pm 36^{*}$ \\
Medulla & & & \\
$\quad$ Dorsal vagal complex & $193 \pm 15$ & $150 \pm 19$ & $128 \pm 11^{* *}$
\end{tabular}

Data were analyzed by the Student-Newman-Keuls multiple range test following 1-way ANOVA, Cochran's $C$ test, and the Bartlett Box $F$ test for homogeneity of variance, except for the data on the ventral tegmental area, which were analyzed by 1 -way $\Lambda$ NOV $\Lambda$ and Student's $t$ test (2-tailed). Ten determinations were obtained for all brain regions except the dorsal raphe and ventral tegmental area, for which 5 determinations were obtained.

* Significantly different from controls but not from one another, $p<0.001$.

** Significantly different from controls but not from acute stress group, $p<0.025$.

level of CRF-LI in their study was $300 \mathrm{pg} / \mathrm{mg}$ protein. They measured CRF-LI in 27 of the 36 regions examined in the present study. For 9 of these 27 common regions, including the frontal cortex, the hippocampus, and the nucleus accumbens, Palkovits et al. (1985) reported levels of CRF-LI below the limits of detection of their assay. In the present study, CRF-LI was detected in each of these regions in concentrations ranging from 22 to $190 \mathrm{pg} / \mathrm{mg}$ protein. In the remaining 18 regions in common, consistently lower (by 2-7-fold) concentrations of CRFLI wcre detected in the present study. Only in the PVN nucleus were similar results attained. In the median eminence, for example, Palkovits et al. (1985) reported almost 8-fold more CRFLI than was detected in the present study in the arcuate nucleus/ median eminence complex.

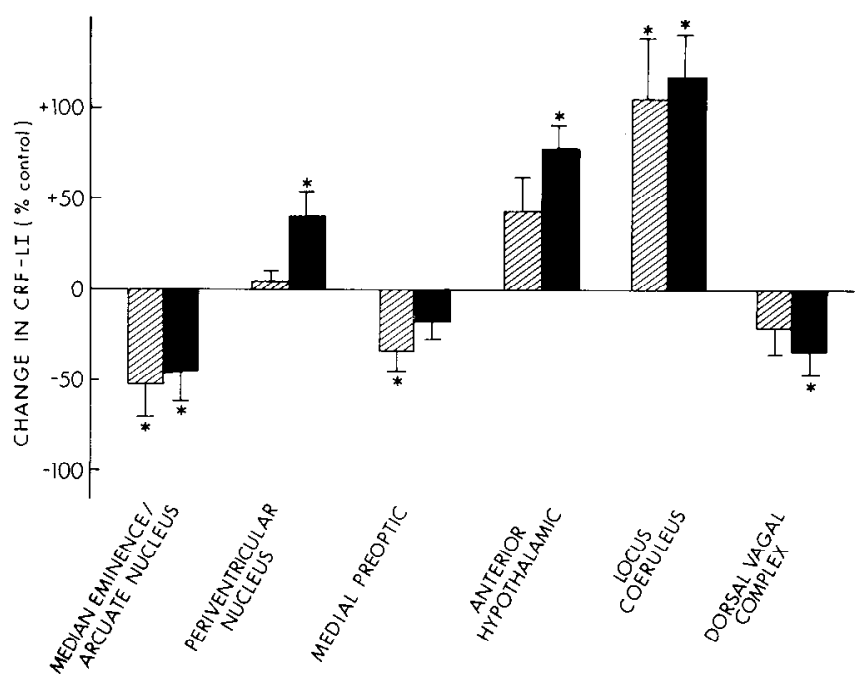

Figure 1. Percentage from baseline of stress-induced change in CRFLI concentration. Hatched bars represent acute stress. Solid bars represent chronic stress. *, Significantly different from controls, $p<0.05$. 
The discrepancies between the present findings and those of Palkovits et al. (1985) may partially be explained by a recent study by Skofitsch and Jacobowitz (1985) in which CRF-LI concentrations were determined by RIA in 50 discrete rat brain regions, using 4 antisera prepared from either synthetic rat/ human or ovine CRF. CRF-LI was identified in 26 of 50 regions by all 4 antisera, though dissimilar concentrations were frequently obtained for a given region using different antisera. In 18 of 50 regions, CRF-LI was detectable only with ovine CRF antisera. Similarly, Palkovits et al. (1985), who employed an antibody to rat CRF, reported that CRF-LI was undetectable in 9 regions in which CRF-LI was detected in the present study, which used an antiserum to ovine CRF. Skofitsch and Jacobowitz (1985) suggest that such discrepant results between RIAs using different antisera may indicate either that heterogeneous forms of the peptide are present or that the antisera are differentially affected by interfering substances from tissue extracts.

In addition, the inherent differences in micropunch surveys performed by different individuals are likely to have significantly contributed to the discrepancies between the present findings and those of Palkovits et al. (1985). It has also been reported that RIAs with antisera such as oC 30 detect rat CRF very poorly when ${ }^{125}$ I-labeled oCRF is used as the tracer, but are quite sensitive to rat/human CRF when ${ }^{125}$ I-labeled rat/human CRF is used, as in the present study (Vale et al., 1983a). The greater sensitivity of the present assay may be due in part to the use of goat anti-rabbit serum instead of Pansorbin to precipitate the CRF antiserum. Finally, differences in extraction techniques may also have contributed to the discrepant findings.

The present RIA results are generally concordant with the findings of previous immunohistochemical studies, though, as discussed by Skofitsch and Jacobowitz (1985), many variables preclude a perfect correlation between the 2 techniques. Such studies have repeatedly demonstrated that the largest collection of CRF-containing cells and fibers in the rat brain is found in the parvocellular division of the PVN nucleus (Bloom et al., 1982; Merchenthaler, 1984; Merchenthaler et al., 1983; Olschowka et al., 1982; Swanson et al., 1983). In addition, a characteristic extrahypothalamic distribution of CRF-containing cells and fibers in close association with limbic parts of the telencephalon and with brain stem centers believed to be involved in the regulation of autonomic responses has been described (Swanson et al., 1983). CRF-positive neurons have been found in all regions of the neocortex and appear to be more numerous in the prefrontal, cingulate, and entorhinal areas (Merchenthaler, 1984; Swanson et al., 1983).

In the basal telencephalon, a large collection of cells that stained for CRF has been described in the central nucleus of the amygdala, the bed nucleus of the stria terminalis, and the substantia innominata-all areas found to contain substantial concentrations of CRF-LI in the present study. In the diencephalon, apart from the paraventricular nucleus, the most numerous CRF-positive neurons were detected in the MPO and periventricular nuclei (Merchenthaler, 1984). In addition, a large CRFpositive cell cluster has been localized to the preoptic-septal region and found to be continuous latcrally with the bed nuclcus of the stria terminalis, caudally with the periventricular nucleus, and rostrally with the septal area (Petrusz et al., 1985). These observations are compatible with the present finding that the periventricular nucleus contains the second highest concentrations of CRF-LI in the hypothalamus after the PVN, and that the MPO area also contains an appreciable concentration of CRF-LI.

In the mesencephalon, the majority of CRF-positive neurons have been identified in the periaqueductal gray and ventral tegmental area, while scattered cells were reported in the dorsal raphe nucleus (Merchenthaler, 1984). Among the midbrain/brain stem regions examined in this study, the high concentrations of CRF-LI were found in the raphe nuclei, ventral tegmental area, and the periaqueductal gray.

In the pons and medulla, the largest collections of CRF-immunopositive cells and fibers were detected in the LC, the parabrachial nuclei, the nucleus of the solitary tract, and the DVC (Merchenthaler, 1984; Swanson et al., 1983). The RIA results in the present study are consistent with this distribution.

As expected, acute stress produced a rise in circulating corticosterone, accompanied by an increase in ACTH concentrations. By contrast, chronic exposure to unpredictable stressors resulted in a significant elevation of plasma corticosterone concentration, while plasma ACTH concentrations returned to baseline. These results are compatible with earlier work by Katz (1980, 1982) and Katz et al. (1981), who used a similar model of unpredictable stress. In contrast to acute stress, chronic stress was associated with significant adrenal hypertrophy, a finding concordant with earlier work demonstrating that adrenal weight can be used as an index of chronic stress (Daniels-Severs et al., 1973) and that, together with the failure of plasma corticosterone to return to baseline, indicates that the chronically stressed animals did not become tolerant to the regimen of unpredictable stressors.

It is interesting to note that, taken together, the effects of chronic, unpredictable stress on the HPA axis in rats are not dissimilar to those observed in severely depressed psychiatric patients. Gold et al. (1984) have reported that, compared to controls, depressed patients tended to have higher mean cortisol values, while ACTH levels remained normal. Gold et al. (1984) also described a decrease in the ratio of ACTH to cortisol values in depressed patients, which was interpreted as compatible with the hypertrophy of the adrenals induced by chronic hyperstimulation with ACTH.

Changes in CRF-LI concentrations were found in several hypothalamic and brain stem nuclei following acute and chronic stress. Remarkably, changes in response to chronic stress were very similar to those induced by acute stress (see Fig. 1). However, a regimen of chronic, unpredictable stressors, which has been shown to produce behavioral and neuroendocrine changes in rats similar to endogenous depression in humans, was designed to circumvent the usual adaptive mechanisms elicited by the intermittent exposure of an animal to a single type of stressor (Katz and Roth, 1979; Katz et al., 1981). This being the case, the changes described in CRF-LI in rats exposed to a variety of stressors might differ significantly from those found in rats intermittently exposed to a single stressor. This could explain the similarity of effect of both acute and chronic stress in the present study.

In the hypothalamus, acute stress produced alterations in CRFLI concentrations in only 2 regions, the arcuate nucleus/ME and the MPO nucleus. Consistent with the proposed role of CRF in the regulation of the release of ACTH and other pro-opiomelanocortin-derived peptides from the anterior pituitary, acute stress produced a $52 \%$ reduction in CRF-LI in the arcuate nucleus/ME. This was presumably due to the stress-enhanced relcase of CRF-LI from nerve terminals in the ME into the hypothalamo-hypophysial portal circulation to activate the pituitary-adrenal axis. Because chronic stress did not totally deplete CRF-LI from the arcuate nucleus/ME, it can reasonably be assumed that there was ongoing or increased synthesis and transport of CRF-LI to the ME.

It is of interest that acute stress caused no significant change in the concentration of CRF-LI in the PVN, where the majority of CRF-containing cell bodies that project to the ME are localized. This suggests the existence in the terminals of the ME of a readily releasable pool of CRF-LI, which is rapidly depleted when the animal is exposed to acute stress. The fact that, com- 
pared to the lack of effect of acute stress, only a trend towards a decrease in CRF-LI is seen in the PVN after chronic stress suggests that adaptive changes in the rate of synthesis, processing, and transport of the peptide in this cell-body-rich region may develop over a longer period of time and may not be acutely detectable.

The decrease in CRF-LI in the MPO with acute stress is also intriguing, especially in view of the recent description (Petrusz, 1985) of a CRF-positive cell cluster, possibly larger than any previously described, located in the preoptic-septal area and centered in the MPO and periventricular preoptic nucleus. Similarly, Swanson et al. (1983) found the most intensely stained CRF-containing fibers in the rat brain in the dorsal parts of the MPO and the adjacent MPO nucleus. A decrement in CRF-LI in this region after acute stress is consistent with previous findings that have implicated the preoptic-septal region in the stress response (Saavedra, 1982; Saavedra et al., 1979; Seggie et al., 1974). One plausible hypothesis is based on the fact that fibers from this area are known to project to the median eminence (Lechan et al., 1982). If a circuit from the MPO, in contrast to the PVN, were selectively activated in the response to acute stress, the decrease in CRF-LI in this region might be caused by synthesis uncompensated by rapid axonal transport of CRFLI to the ME.

Changes in the levels of CRF-LI in hypothalamic nuclei were accompanied by changes in CRF-LI in brain stem nuclei that are rich in norepinephrine-containing cells and have been implicated in the stress response (Ganong, 1984; Palkovits et al., 1975). Both acute and chronic stress have identical effects on the LC, where CRF-LI concentrations were doubled under both conditions. Chronic stress, in addition, produced a $30 \%$ decrease in CRF-LI in the DVC, which encompasses the nucleus of the solitary tract in which the $\mathrm{A}_{2}$ catecholaminergic cell group is embedded (Kvetnansky et al., 1978).

The possibility that CRF might be involved in the regulation of the autonomic nervous system is suggested by the distribution of the peptide in the CNS. Swanson et al. (1983) reported that CRF-containing cells and fibers were closely associated with cell clusters in the basal forebrain, hypothalamus, pons, and medulla, which are believed to have an important role in the integration of autonomic responses. Special emphasis was given to the role of the nucleus of the solitary tract, which (1) receives a direct sensory input from the vagal and glossopharyngeal nerves; (2) gives rise to a widespread, noradrenergic projection to the parvocellular subdivision of the PVN and other basal forebrain nuclei; and (3) may be involved in the relay of sensory information to, and coordination of responses from, CRF-stained cell clusters in this region. In addition, intracerebroventricular administration of CKF elevates plasma epinephrine and norepinephrine and increases arterial pressure and heart rate (Brown and Fisher, 1985; Brown et al., 1982). Our finding that chronic stress produces a decrease in CRF-LI in the DVC is consistent with a proposed role for CRF in the regulation of the autonomic nervous system and its response to stress.

The LC, which consists almost entirely of noradrenergic neurons and projects widely throughout the neuraxis, including the parvocellular subdivision of the PVN (Foote et al., 1983), has also been repeatedly implicated in the stress response and arousal functions (Glavin, 1985; Korf et al., 1973; Thierry et al., 1968; Weiss et al., 1981). CRF-positive fibers and cells have been detected in the LC (Swanson et al., 1983), and Valentino et al. (1983) found that CRF increased the discharge rates of LC neurons. We found that both acute and chronic stress increased CRF-LI in the LC. Whether this increase was due to increased translation or to increased prohormone-to-final hormone posttranslational processing, to decreased release, or to decreased catabolism remains to be determined, at least in part, by future characterization of the immunoreactive forms involved and of mRNA levels. However, our findings in the LC do provide additional support for the proposed role of CRF in the central integration of the stress response.

Finally, the close anatomical association of CRF-positive cells and fibers with adrenergic cells and processes has drawn frequent comment (Merchenthaler, 1984), and there have been speculations regarding functional relationships. Such speculations are buttressed by the finding that CRF can alter firing rates of LC noradrenergic neurons (Valentino et al., 1983). It has also been established by dual staining procedures that CRF-positive neurons are distinct from those containing serotonin and dopamine beta hydroxylase (Merchenthaler et al., 1983). The present findings are generally supportive of a functional relationship between the CRF system and the noradrenergic system in particular, although elucidation of the details of this relationship will require further work.

\section{References}

Baldessarini, R. J. (1983) Biomedical Aspects of Depression, American Psychiatric Press, Washington, DC

Bloom, F. E., E. F. Battenberg, J. Rivier, and W. W. Vale (1982) Corticotropin releasing factor (CRF): Immunoreactive neurones and fibers in rat hypothalamus. Regul. Peptides 4: 43-48.

Britton, D. R., G. F. Koob, and J. Rivier (1982) Corticotropin releasing factor enhances behavioral effects of novelty. Life Sci. 31: 363-367.

Brown, M. R., and L. A. Fisher (1985) Corticotropin-releasing factor: Fffect on the autonomic nervous system and visceral systems. Fed. Proc. 44: 243-248.

Brown, M. R., L. A. Fisher, J. Spiess, C. Rivier, J. Rivier, and W. Vale (1982) Corticotropin-releasing factor: $\Lambda$ ctions on the sympathetic nervous system and metabolism. Endocrinology 111: 928-931.

Carroll, B. J., G. C. Curtis, and J. Mendels (1976) Neuroendocrine regulation in depression. I. Limbic system-adrenal cortical dysfunction. Arch. Gen. Psychiatry 33: 1039-1044.

Cummings, S., R. Elde, J. Ellis, and A. Lindall (1983) Corticotropinreleasing factor immunoreactivity is widely distributed within the central nervous system of the rat: An immunohistochemical study. J. Neurosci. 3: 1355-1368.

Daniels-Severs, A., A. Goodwin, L. C. Keil, and J. Vernikos-Danellis (1973) Effect of chronic crowding and cold on the pituitary-adrenal system: Responsiveness to an acute stimulus during chronic stress. Pharmacology 9: 348-356.

Ehlers, C. L., S. J. Henriksen, M. Wang, J. Rivier, W. Vale, and F. E. Bloom (1983) Corticotropin releasing factor produces increases in brain excitability and convulsive seizures in rats. Brain Res. 278: 332-336.

Fischman, A. J., and L. Moldow (1982) Extrahypothalamic distribution of CRF-like immunoreactivity in the rat brain. Peptides 1 : 149-153.

Fisher, L. A., J. Kivier, C. Rivier, J. Spiess, W. Vale, and M. R. Brown (1982) Corticotropin-releasing factor (CRF): Central effects on mean arterial pressure and heart rate in rats. Endocrinoloy 10: 2222-2224.

Foote, S. L., F. E. Bloom, and G. Aston-Jones (1983) Nucleus locus coeruleus: New evidence of anatomical and physiological specificity. Physiol. Rev. 63: 844-914.

Ganong, W. F. (1984) Neurotransmitter mechanisms underlying stress responses. In Neuroendocrinology and Psychiatric Disorders, G. M. Brown, S. Koslow, and S. Reichlin, eds., pp. 133-143, Raven, New York.

Gibbs, D. M., and W. Vale (1982) Presence of corticotropin releasing factor-like immunoreactivity in hypophysial portal blood. Endocrinology 111: 1418-1420.

Glavin, G. B. (1985) Stress and brain noradrenaline: A review. Neurosci. Biobehav. Rev. 9: 233-243.

Glowinski, J., and L. L. Iversen (1966) Regional studies of catecholamines in the rat brain. I. The disposition of $\left({ }^{3} \mathrm{H}\right)$ norepinephrine, $\left.{ }^{3} \mathrm{H}\right)$ dopamine, and $\left({ }^{3} \mathrm{H}\right)$ DOPA in various regions of the brain. $\mathrm{J}$. Neurochem. 13: 665-669.

Gold, P. W., G. Chrousos, C. Kellner, R. Post, A. Roy, P. Augerinos, H. Schulte, E. Oldfield, and D. L. Loriaux (1984) Psychiatric impli- 
cations of basic and clinical studies with corticotropin-releasing factor. Am. J. Psychiatry 141: 619-627.

Gutkowska, J., J. Julesz, J. St. Louis, and J. Genest (1982) Radioimmunoassay of corticotropin from plasma. Clin. Chem. 28: 22292234.

Harris, G. W. (1948) Neural control of the pituitary gland. Physiol. Rev. 28: 139

Katz, R. J. (1980) Animal model of depression: Effects of electroconvulsive shock therapy. Neurosci. Biobehav. Rev. 5: 246-251.

Katz, R. J. (1982) Animal model of depression: Pharmacological sensitivity of a hedonic deficit. Pharmacol. Biochem. Behav. 16: 965968.

Katz, R. J., and K. Roth (1979) Tail pinch induced stress-arousal facilitates brain stimulation reward. Physiol. Behav. 22: 193-194.

Katz, R. J., K. A. Roth, and B. J. Carroll (1981) Acute and chronic stress effects on open field activity in the rat: Implications for a model of depression. Neurosci. Biobehav. Rev. 5: 247-251.

Korf, J., G. K. Aghajanian, and R. H. Roth (1973) Increased turnover of norepinephrine in the rat cerebral cortex during stress: Role of the locus coeruleus. Neuropharmacology 12: 933-938.

Kvetnansky, R., M. Palkovits, A. Mitro, T. Torda, and L. Mikulaj (1977) Catecholamines in individual hypothalamic nuclei of acutely and repeatedly stressed rats. Neuroendocrinology 23: 257-267.

Kvetnansky, R., I. J. Kopin, and J. M. Saavedra (1978) Changes in epinephrine in individual hypothalamic nuclei after immobilization stress. Brain Res. 155: 387-390.

Lechan, R. M., J. L. Nestler, and S. Jacobson (1982) The tuberoinfundibular system of the rat as demonstrated by immunohistochemical localization of retrogradely transported wheat germ agglutinin (WGA) from the median eminence. Brain Res. 245: 1-15.

Levine, A. S., B. Rogers, J. Kneip, M. Grace, and J. E. Morley (1983) Effect of centrally administered corticotropin releasing factor (CRF) on multiple feeding paradigms. Neuropharmacology 22: 337-339.

Lowry, O. H., N. J. Rosebrough, A. L. Farr, and R. J. Randall (1951) Protein measurement with the Folin phenol reagent. J. Biol. Chem. 193: 265-275.

Merchenthaler, I. (1984) Corticotropin releasing factor (CRF)-like immunoreactivity in the rat central nervous system: Extra-hypothalamic distribution. Peptides 5: 53-69.

Merchenthaler, I., S. Vigh, P. Petrusz, and A. V. Shally (1983) The paraventriculo-infundibular corticotropin releasing factor (CRF) pathway as revealed by immunocytochemistry in long-term hypophyscctomized or adrenalcctomized rats. Regul. Peptides 5: 295-305.

Moldow, R. L., and A. J. Fischman (1982) Radioimmunoassay of CRF-like material in rat hypothalamus. Peptides $3: 37-39$.

Murphy, B. E. P. (1967) Some studies of the protein binding of steroids and their application to the routine micro and ultramicro measurement of various steroids in body fluids by competitive protein binding radioassay. J. Clin. Endocrinol. Metab. 27: 973-990.

Nemeroff, C. B., D. E. Hernandez, R. C. Orlando, and A. J. Prange, Jr. (1982) Cytoprotective effect of centrally administered neurotensin in rats. Amer. J. Physiol. 242: 6342-6346.

Nemeroff, C. B., E. Widerlöv, G. Bissette, H. Walleus, I. Karlsson, K. Eklund, C. D. Kilts, P. T. Loosen, and W. Vale (1984) Elevated concentrations of CSF corticotropin-releasing factor-like immunoreactivity in depressed patients. Science $226: 1342-1343$.

Olschowka, J. A., T. L. O'Donohuc, G. P. Mueller, and D. M. Jacobowitz (1982) Hypothalamic and extrahypothalamic distribution of CRF-like immunoreactive neurons in the rat brain. Neuroendocrinology 35: 305-308.

Orth, D. N. (1978) Adrenocorticotrophic hormone (ACTH). In Methods of Hormone Radioimmunoassay, B. M. Jaffe and H. R. Behrman, eds., pp. 245-284, Academic, New York.

Palkovits, M. (1973) Isolated removal of hypothalamic or other brain nuclei of the rat. Brain Res. 59: 449-450.

Palkovits, M., and M. J. Brownstein (1983) Microdissection of brain areas by the punch technique. In Brain Microdissection Techniques, A. C. Cuello, ed., pp. 1-36, Wiley, New York.

Palkovits, M., R. M. Kobayashi, J. S. Kizer, D. M. Jacobowitz, and I. J. Kopin (1975) Effects of stress on catecholamines and tyrosine hydroxylase activity of individual hypothalamic nuclei. Neuroendocrinology 18: 144-153.
Palkovits, M., M. J. Brownstein, and W. Vale (1985) Distribution of corticotropin-releasing factor in rat brain. Fed. Proc. 44: 215-219.

Petrusz, P., I. Merchenthaler, J. L. Maderdrut, and P. U. Heitz (1985) Central and peripheral distribution of corticotropin-releasing factor. Fed. Proc. 44: 229-235.

Remington, R. D., and M. A. Schork (1970) Statistics with Applications to the Biological and Health Sciences, Prentice-Hall, Englewood Cliffs, NJ.

Ritchie, J. C., B. J. Carroll, P. R. Olton, U. Shively, and M. Feinberg (1985) Plasma cortisol determination for the dexamethasone suppression test. Arch. Gen. Psychiatry 42: 1985.

Rivier, C., M. Brownstein, J. Spiess, J. Rivier, and W. Vale (1982a) In vivo corticotropin-releasing factor-induced secretion of adrenocorticotropin, beta-endorphin, and corticosterone. Endocrinology 110: 272-278.

Rivier, C., J. Rivier, and W. Vale (1982b) Inhibition of adrenocorticotropic hormone secretion in the rat by immunoneutralization of corticotropin-releasing factor. Science 218: 377-379.

Saavedra, J. M. (1982) Changes in dopamine, noradrenaline and adrenaline in specific septal and preoptic nuclei after acute immobilization stress. Neuroendocrinology 35: 396-401.

Saavedra, J. M., R. Kvetnansky, and I. J. Kopin (1979) Adrenaline, noradrenaline and dopamine levels in specific brain stem areas of acutely immobilized rats. Brain Res. 160: 271-280.

Sawchenko, P. E., and L. W. Swanson (1985) Localization, colocalization, and plasticity of corticotropin-releasing factor immunoreactivity in rat brain. Fed. Proc. 44: 221-227.

Seggie, J., J. Uhlir, and G. M. Brown (1974) Adrenal stress responses following septal lesions in the rat. Neuroendocrinology 16: 225-236.

Sirinathsinghji, D. J. S., L. H. Rees, J. Rivier, and W. Vale (1983) Corticotropin-releasing factor is a potent inhibitor of sexual receptivity in the female rat. Nature 305: 230-235.

Skofitsch, G., and D. M. Jacobowitz (1985) Distribution of corticotropin releasing factor-like immunoreactivity in the rat brain by immunohistochemistry and radioimmunoassay: Comparison and characterization of ovine and rat/human CRF antisera. Peptides 6: 319336.

Sutton, R. E., G. F. Koob, M. LeMoal, J. Rivier, and W. Vale (1982) Corticotropin-releasing factor produces behavioral activation in rats. Nature 297: 331-333.

Swanson, L. W., P. E. Sawchenko, J. Rivier, and W. W. Vale (1983) Organization of ovine corticotropin-releasing factor immunoreactive cells and fibers in the rat brain: An immunohistochemical study. Neuroendocrinology 36: 165-186.

Thierry, A., F. Javoy, J. Glowinski, and S. Kety (1968) Effects of stress on the metabolism of norepinephrine, dopamine, and serotonin in the central nervous system of the rat. I. Modification of norepinephrine turnover. J. Pharmacol. Exp. Ther. 163: 163-171.

Uphouse, L. L., C. B. Nemeroff, G. A. Mason, A. J. Prange, Jr., and S. C. Bondy (1982) Interactions between "handling" and acrylamide on endocrine response in rats. Neurotoxicology 3:121-125.

Vale, W., J. Spiess, C. Rivier, and J. Rivier (1981) Characterization of a 41-residue ovine hypothalamic peptide that stimulates secretion of corticotropin and beta-endorphin. Science 213: 1394.

Vale, W., J. Vaughan, M. Smith, G. Yamamoto, J. Rivier, and C. Rivier (1983a) Effects of synthetic ovine corticotropin-releasing factor, glucocorticoids, catecholamines, neurohypophisial peptides, and other substances on cultured corticotropic cells. Endocrinology 113: 11211131

Vale, W., J. Vaughan, G. Yamamoto, T. Bruhn, C. Douglas, D. Dalton, C. Rivier, and J. Rivier (1983b) Assay of corticotropin releasing factor. Meth. Enzymol. 103: 565-577.

Valentino, R. J., S. L. Foote, and G. Aston-Jones (1983) Corticotropinreleasing factor activates noradrenergic neurons of the locus coeruleus. Brain. Res. 270: 363-367.

Weiss, J. M., P. A. Goodman, B. G. Losito, S. Corrigan, J. M. Charry, and W. H. Bailey (1981) Behavioral depression produced by an uncontrollable stressor: Relationship to norepinephrine, dopamine, and serotonin levels in various regions of rat brain. Brain Res. Rev. 3: 167-205. 